\title{
Simulations of SiC CVD - Perspectives on the need for surface reaction model improvements
}

\author{
Örjan Danielsson, Olle Kordina and Erik Janzén
}

\section{Linköping University Post Print}

\section{Tweet}

N.B.: When citing this work, cite the original article.

Original Publication:

Örjan Danielsson, Olle Kordina and Erik Janzén, Simulations of SiC CVD - Perspectives on the need for surface reaction model improvements, 2014, SILICON CARBIDE AND RELATED MATERIALS 2013, PTS 1 AND 2, 218-221. http://dx.doi.org/10.4028/www.scientific.net/MSF.778-780.218 Copyright: (0 (2014) Trans Tech Publications, Switzerland Publisher URL: http://www.scientific.net/

Postprint available at: Linköping University Electronic Press http://urn.kb.se/resolve?urn=urn:nbn:se:liu:diva-108195 


\title{
Simulations of SiC CVD - Perspectives on the need for surface reaction model improvements
}

\author{
Örjan Danielsson ${ }^{a}{ }^{*}$, Olof Kordina ${ }^{\mathrm{b}}$, Erik Janzén ${ }^{\mathrm{c}}$ \\ Department of Physics, Chemistry and Biology, Linköping University, Sweden \\ a orjan.danielsson@liu.se, ${ }^{b}$ olof.kordina@liu.se, ${ }^{\circ}$ erik.janzen@liu.se
}

Keywords: Epitaxial growth, Chemical Vapor Deposition, Modeling, Simulation, Surface chemistry

\begin{abstract}
Simulations of $\mathrm{SiC}$ chemical vapor deposition is an excellent tool for understanding, improving and optimizing this complex process. However, models used up to date have often been validated for one particular set of process parameters, often in the silicon limited growth regime, in one particular growth equipment. With chlorinated precursors optimal growth condition is often found to take place at the border between carbon limited and silicon limited regimes. At those conditions the previous models fail to predict deposition rates properly. In this study we argue that molecules like $\mathrm{C}_{2} \mathrm{H}_{2}, \mathrm{C}_{2} \mathrm{H}_{4}$ and $\mathrm{CH}_{4}$, actually might react with the surface with much higher rates than suggested before. Comparisons are made between the previous model and our new model, as well as experiments. It is shown that higher reactivities of the hydrocarbon molecules will improve simulation results as compared to experimental findings, and help to better explain some of the trends for varying $\mathrm{C} / \mathrm{Si}$ ratios.
\end{abstract}

\section{Introduction}

Simulations of $\mathrm{SiC}$ chemical vapor deposition (CVD) have over the years been used to increase the understanding of this complex process. Simulations have also been used for improving and optimizing process equipment and growth conditions. To make the SiC CVD process industrially competitive, improvements and optimizations are indeed needed. A better understanding of the chemistry of the CVD process is particularly important to be able to improve and control the growth process, and to optimize growth equipment design. Through computational models the process can be studied in great detail, provided the models are good enough. Models implemented in the context of computational fluid dynamics (CFD) have successfully been used to simulate both gas-phase and surface chemistry for epitaxial growth of SiC by CVD [1, 2, 3]. However, these models have often been validated for one particular set of process parameters in one particular growth equipment. Therefore, it is uncertain if these models give accurate predictions outside the conditions used for validation. For example, one evident proof of the shortcomings of the existing models for CVD growth of $\mathrm{SiC}$ is the inability to correctly model the hydrocarbon gas-phase chemistry, as previously reported [4]. To develop the understanding of the SiC CVD process further, the models need to be updated and refined, as pointed out in a recent paper [5], so that experimental findings can be well predicted, regardless of reactor configuration, precursors or process conditions. In this paper we discuss the need for surface reaction model improvements.

The model by Allendorf and Kee [6] is one of the most detailed models of the SiC CVD chemistry published to date, and it has been the basis for several other simulation studies during the past 10-15 years $[1,2,3,7]$. Yet, it contains several questionable assumptions due to the lack of theoretical and experimental data on surface reaction rates and paths for SiC. In the model [6], the surface reaction rates are based on reactive sticking coefficients (probabilities), which were taken from experimental studies of reactions with silicon surfaces at relatively low temperatures. Both Allendorf and Kee [6], as well as Löfgren et al [7] who used the same model, came to the conclusion that this model predicts carbon limited growth, while a silicon limited growth would be expected based on experiments at the same conditions which shows that model improvements are necessary. 
When the $\mathrm{SiC}$ epitaxial growth is limited by silicon it is possible to obtain accurate results from the simulations by only including silicon containing species in the surface reaction model [1]. However, with the relatively new concept of chlorinated chemistry in SiC CVD growth [8], and recent experimental findings on the possibility to obtain high quality $\mathrm{SiC}$ epitaxial layers using $\mathrm{CH}_{4}$ as carbon precursor [9], the optimal growth condition is often found to take place at the border between carbon limited and silicon limited regimes. To use simulations for making predictions of growth rates and deposition distributions also in these cases, improvements in the surface reaction models are needed.

\section{Model setup}

Computational Fluid Dynamics (CFD), where partial differential equations for conservation of mass, momentum and energy are solved numerically over a computational grid, was used to analyze the flow, temperature and mass transport in a typical CVD reactor. A 2D geometrical model of a horizontal hot-wall $\mathrm{SiC} \mathrm{CVD}$ reactor, running at 100 mbar, using $\mathrm{SiH}_{4}+\mathrm{C}_{2} \mathrm{H}_{4}$ as precursors highly diluted in $\mathrm{H}_{2}$ carrier gas, was used for all simulations. The susceptor temperature profile used (taken from actual measurements) has a parabolic shape along the gas flow direction, with the peak of $1625^{\circ} \mathrm{C}$ at about $60 \%$ of the total length of the susceptor (downstream). The temperatures at the entrance and exit of the susceptor are $1310^{\circ} \mathrm{C}$ and $1355^{\circ} \mathrm{C}$, respectively. Simulations were done for varying inlet $\mathrm{C} / \mathrm{Si}$ ratios, with a constant inlet mole fraction of $\mathrm{SiH}_{4}$.

Chemical reactions in the gas-phase are accounted for by source terms in the mass transport equation. A detailed gas-phase reaction model consisting of more than 200 elementary reaction steps is used. Reactions with the surface are considered as boundary conditions for mass fractions of gas-phase species, rather than as a source term in the transport equations. Generally, surface reaction rates can be estimated based on the species flux to the surface, times a so-called sticking probability (or sticking coefficient). With this simplification, the only necessary input to the CFD simulations is the sticking probability for each molecule. This approach is used in the new model set up in this work, as well as in most previous models.

\section{Results and discussion}

A comparison between simulations using the model from Allendorf and Kee [6], which has been most frequently used in simulations of SiC CVD growth to date, and a new model suggested by us will be shown below. Particularly the deposition rate along the gas flow direction vs. inlet $\mathrm{C} / \mathrm{Si}$ ratio is studied. This is done by varying the $\mathrm{C}_{2} \mathrm{H}_{4}$ flow rate, while keeping a constant $\mathrm{SiH}_{4}$ flow rate.

Previous model. It is observed in Fig. 1a, where the model from Allendorf and Kee [6] is used, that the predicted deposition rate upstream in the susceptor is relatively low (towards the left in the figure). This is in stark contrast to experiments, where quite substantial depositions occurs upstream of the substrate. When plotting the growth rate at the substrate position (at $60 \%$ of total susceptor length) vs. inlet $\mathrm{C} / \mathrm{Si}$ ratio, as in Fig. 2 , it is seen that for $\mathrm{C} / \mathrm{Si}>1.5$ the growth rate decreases with increasing $\mathrm{C} / \mathrm{Si}$ for this model. This is also in contrast to experimental experience, where a constant growth rate is expected for a constant $\mathrm{SiH}_{4}$ flow rate above this $\mathrm{C} / \mathrm{Si}$ ratio. In the figures the growth rate is normalized so that the growth rate for $\mathrm{C} / \mathrm{Si}=3.5$ is equal to one at the substrate position.

In the model, silicon species are assumed to be very reactive, with a sticking coefficient equal to one; all silicon molecules hitting the surface will be adsorbed. But the surface reaction model is constructed in such a way that silicon species can only react with carbon adsorbed on the surface, and vice versa. Therefore, if no carbon species will be adsorbed, then the silicon species have no place to go, and consequently no deposition will occur. Instead, an over prediction of silicon in the gas-phase further downstream (e.g. at the wafer position) will be the result. This artificially high abundance of silicon leads to a prediction of carbon limited growth, even for conditions experimentally known to give silicon limited growth. This was found both by Allendorf and Kee [6], and by Löfgren et al [7] using this model, and this is also what we find in the present study, see 
Fig. 2. The results shown here where the model predicts growth rates up to $150 \%$ of normal values at the substrate position are in line with the findings in [7].

The low upstream growth rate predicted by the simulations is thus concluded to be caused by the low sticking probability of hydrocarbons. In the upstream area $\mathrm{CH}_{4}$ and $\mathrm{C}_{2} \mathrm{H}_{4}$ are the dominant hydrocarbons; as compared to $\mathrm{C}_{2} \mathrm{H}_{2}$ in the downstream area [5]. In the surface reaction model by Allendorf and Kee, the sticking probabilities of $\mathrm{C}_{2} \mathrm{H}_{4}$ and $\mathrm{CH}_{4}$ are set to $1.6 \cdot 10^{-3}$ and $5 \cdot 10^{-5}$, respectively. These values were determined from experiments of adsorption on silicon substrates in the temperature interval $1062-1227 \mathrm{~K}$ [10]. For $\mathrm{C}_{2} \mathrm{H}_{2}$ the value 0.02 from Mogab and Leamy [11] is used, which was obtained for Si substrates in a UHV system at below $1373 \mathrm{~K}$. These values have been used in most models of SiC CVD growth published to date, and have never been questioned. However, these experiments were done at low temperatures, on a different substrate and without hydrogen in the atmosphere. These facts, in combination with the predictions obtained which contradict experimental findings make us question the usability of these values for actual conditions of homoepitaxial SiC CVD growth.

a)

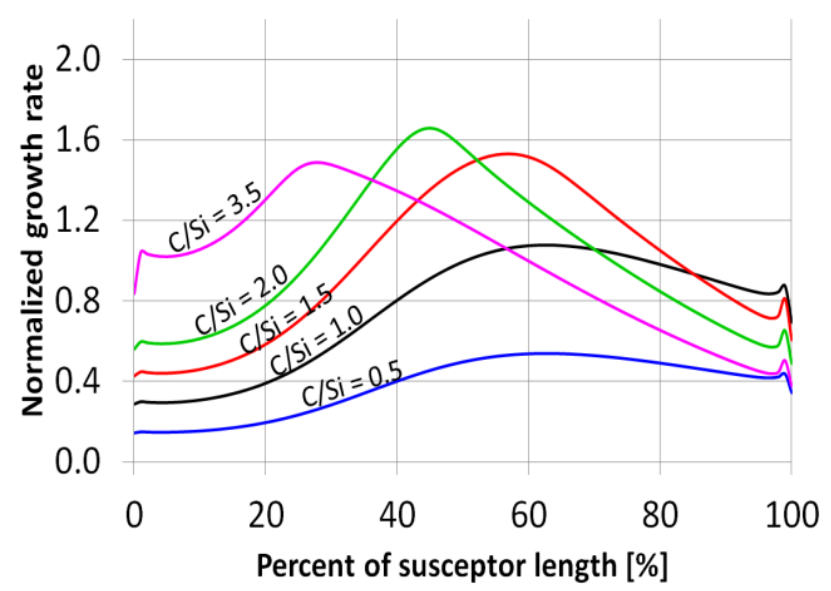

b)

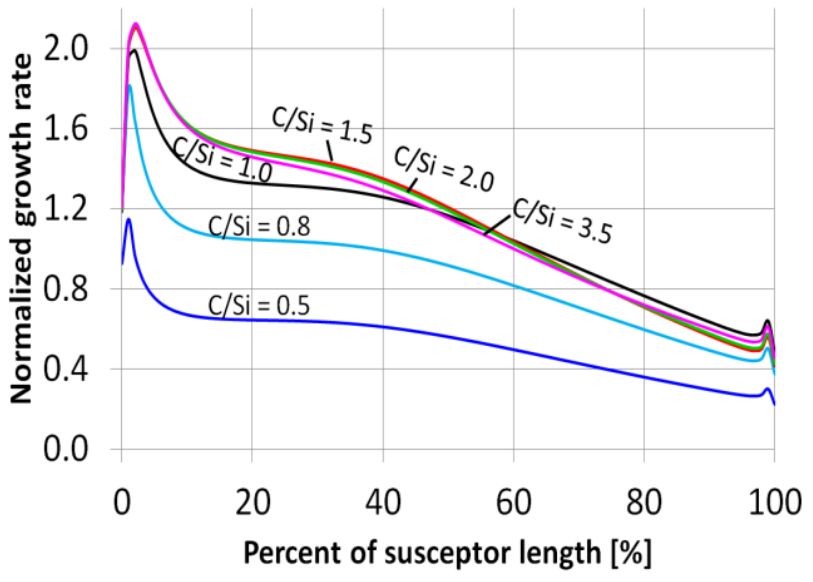

Fig. 1 Normalized predicted growth rate profiles along the gas-flow direction for varying $\mathrm{C} / \mathrm{Si}$ ratios (silane flow constant). a) Model by Allendorf and Kee [6], and b) Our new model.

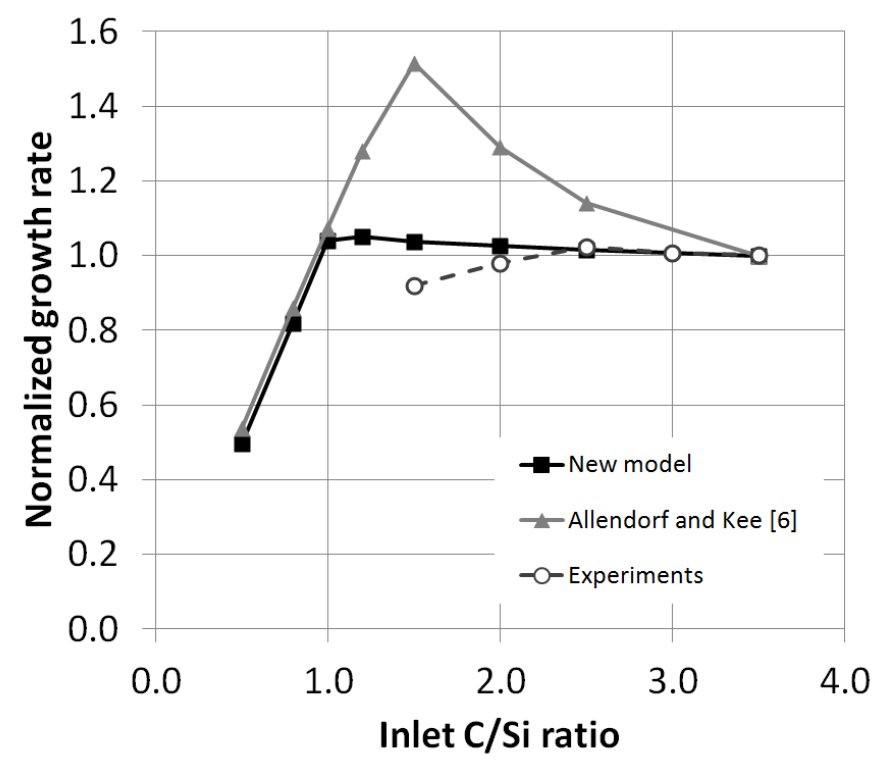

Fig. 2 Normalized predicted and experimental growth rates at $60 \%$ of total susceptor length. Experimental data were taken from doping studies, where a constant $\mathrm{N}_{2}$ flow was used. The relatively high n-type doping levels resulting at lower $\mathrm{C} / \mathrm{Si}$ ratios influences the growth rate negatively. 
Updated model. Clearly, a more reliable model must take into account a larger depletion of silicon upstream from the substrate, so that the switch from carbon to silicon limited growth is well predicted and in agreement with experiments. Allowing $\mathrm{Si}$ to deposit on $\mathrm{Si}$ in the model would surely lead to a larger depletion of silicon upstream. In fact, if we still assume a high reactivity of silicon species, almost all silicon would deposit early in the susceptor. This would lead to a relatively high concentration of carbon, as compared to silicon, at the substrate position, and thus the simulations would predict silicon limited growth also for relatively low $\mathrm{C} / \mathrm{Si}$ ratios. This approach would not improve the model, since the switch from carbon to silicon limited growth is known to occur somewhere between $\mathrm{C} / \mathrm{Si}=0.9-1.2$ in most reactor configurations. Therefore we suggest that the only reasonable assumption would be that the hydrocarbons are in fact much more reactive than previously suggested. If we assume higher sticking coefficients for $\mathrm{CH}_{4}, \mathrm{C}_{2} \mathrm{H}_{4}$ and $\mathrm{C}_{2} \mathrm{H}_{2}$, more carbon would be adsorbed in the upstream region, which would increase the number of places for the silicon species to attach to. Thus, more of the silicon will be deposited further upstream, and therefore the depletion of silicon will be larger, but still not too large. This will shift the predicted transition from silicon to carbon limited growth towards lower inlet $\mathrm{C} / \mathrm{Si}$ ratios.

To test the implications of our speculations above, we have constructed a new surface reaction model, where the sticking probabilities for $\mathrm{C}_{2} \mathrm{H}_{4}$ and $\mathrm{CH}_{4}$ are set to 0.1 and for $\mathrm{C}_{2} \mathrm{H}_{2}$ to 0.5 . The assumption that silicon only reacts with adsorbed carbon, and vice versa, on the surface, as suggested in [6], is kept in the new model. This assumption forces $\mathrm{SiC}$ to be deposited everywhere, but this is not too strange since no pure silicon deposits are found experimentally under these conditions. Instead, it is usually $\mathrm{SiC}$ that is deposited also in the upstream region of the susceptor, even though the crystal quality is bad. In the simulation results shown in Fig. 1b, and in Fig. 2, it can be seen that the deposition rate becomes higher in the upstream area (towards the left in Fig. 1b) and that the growth rate vs. C/Si ratio behaves more in line with experiments (Fig. 2).

\section{Summary}

CFD simulations have been performed to predict growth rates for varying $\mathrm{C} / \mathrm{Si}$ ratios. Comparisons between the most frequently used previous surface reaction model and our new model show that higher reactivities of the hydrocarbon molecules will improve simulation results as compared to experimental findings.

\section{Acknowledgements}

Support from the Swedish Foundation for Strategic Research (project SM11-0051) is gratefully acknowledged.

\section{References}

[1] Ö. Danielsson, A. Henry, and E. Janzén, J. Cryst. Growth 243 (2002) 170

[2] S.-i. Nishizawa and M. Pons, Chem. Vap. Deposition 12 (2006) 516

[3] A. Veneroni and M. Masi, Chem. Vap. Deposition 12 (2006) 562

[4] Ö. Danielsson, P. Sukkaew, M. Yazdanfar, O. Kordina and E. Janzén, Mat. Sci. Forum 740742 (2013) 213

[5] Ö. Danielsson, P. Sukkaew, L. Ojamäe, O. Kordina and E. Janzén, Theor. Chem. Acc. 132 (2013) 1398, DOI: 10.1007/s00214-013-1398-9

[6] M. D. Allendorf and R. J. Kee, J. Electrochem. Soc. 138 (1991) 841

[7] P. M. Löfgren, W. Ji, C. Hallin, and C.-Y. Gu, J. Electrochem. Soc. 147 (2000) 164

[8] H. Pedersen, S. Leone, A. Henry, F. C. Beyer, V. Darakchieva and E. Janzén, J. Cryst. Growth 207 (2007) 334

[9] M. Yazdanfar, H. Pedersen, O. Kordina and E. Janzén, ICSCRM 2013, Miyazaki, Japan

[10] C. D. Stinespring and J. C. Wormhoudt, J. Appl. Phys. 65 (1989) 1733

[11] C. J. Mogab and H. J. Leamy, J. Appl. Phys. 45 (1974) 1075 